\title{
A utilização do software E-Chemical como ferramenta educacional de Química.
}

\author{
Ana Caroline Nunes Gomes ${ }^{1}$, André Filipe Coelho de Oliveira ${ }^{1}$ \\ ${ }^{1}$ Universidade do Estado do Amazonas (UEA) - Manaus - AM - Brasil \\ acng.inf@uea.edu.br, afco.inf@uea.edu.br
}

\begin{abstract}
The use of technology in the current educational setting can be a mechanism to promote more dynamic and interactive classes for students. With each passing day, school-age youngsters are becoming increasingly computerized, so using educational software in the classroom can be a way to use something that students like as a way to aid in their learning process. The proposal of this article is to discuss the development of an educational software applied in the discipline of Chemistry to make the student learn about the periodic table and its divisions through a game named "E-Chemical" where it should be said which divisions exist in the Periodic table of elements.
\end{abstract}

Resumo. A utilização de tecnologia no cenário educacional atual pode ser um mecanismo para promover aulas mais dinamizadas e interativas para os alunos. A cada dia que passa os jovens em idade escolar vem se tornando cada vez mais informatizados, com isso, utilizar softwares educacionais em sala de aula pode ser uma forma de utilizar algo que os discentes gostam como um meio de auxiliar no seu processo de aprendizagem. A proposta desse artigo é abordar o desenvolvimento de um software educativo aplicado na disciplina de Química para fazer com que o aluno aprenda sobre a tabela periódica e suas divisões através de um jogo nominado "E-Chemical" onde deverá ser dito quais as divisões existentes na tabela periódica dos elementos.

\section{Cenário de uso}

Com o advento da tecnologia cada dia mais presente no cotidiano das pessoas, torna-se notório o uso de tais ferramentas em todos os campos da vida humana, tais como: saúde, mídias, esportes e educação, sendo este último, o ramo que ainda apresenta mais resistência em arraigar tecnologia em seu procedimento.

A cada dia que passa o homem vem se tornando cada vez mais modernizado, no que diz respeito ao uso de tecnologias. Ao longo dos anos tais artefatos vieram se renovando e ganhando mais espaço na vida do homem. Pimentel (2011) afirma que:

O novo ser humano é digital, deixa de ser reconhecido somente por sua aparência física e passa a ter sua identidade vinculada a um perfil, um endereço de correio eletrônico, um nickname, um avatar. O ser humano do século XXI tem novos comportamentos, novos estilos de ser e agir, lê e escrever de forma diferente, desenvolveu novas formas de pensar e 
VI Congresso Brasileiro de Informática na Educação (CBIE 2017)

Anais dos Workshops do VI Congresso Brasileiro de Informática na Educação (WCBIE 2017)

aprender, de se relacionar com amigos e de amar (PIMENTEL, 2011, p. 3).

A utilização de novos métodos para dinamizar o processo de ensino e aprendizagem é um assunto que deveria ser amplamente discutido, pois, estratégias para auxiliar na aprendizagem do aluno podem fazer do mesmo um sujeito mais ativo na construção de seu conhecimento. Com isso, torna-se importante analisar o impacto do uso de tecnologias no cenário educacional como uma maneira diversificada de auxiliar os alunos em seu processo de aprendizagem, bem como, fazer com que os mesmos aprendam de maneira lúdica e educativa.

Segundo Kishimoto (2008), os brinquedos e as ferramentas lúdicas são de suma importância para o desenvolvimento pessoal e cognitivo da criança, pois, através da brincadeira a mesma aprende, se diverte e também socializa, uma vez que, brincadeiras envolve socialização. Levando para o campo educacional, se um aluno for apresentado a qualquer conteúdo de forma dinâmica e diferenciada, então ele poderá ser capaz de sentirse mais motivado e interessado em aprender a respeito daquele assunto. Com isso posto, introduzir ferramentas educacionais em sala de aula como um mecanismo de auxilio ao professor para exercitar os conteúdos das disciplinas com os alunos é uma maneira de diferenciar o ensino moderno do tradicional ${ }^{1}$, como também, é uma forma de mostrar para o aluno as diversas possibilidades de estudo que ele tem disponível.

Segundo Papert (2008), em seu livro A máquina das crianças, a criança é um "ser pensante" e como tal é capaz de construir seu próprio conhecimento mesmo que seja sem a supervisão de outrem, segundo ele também, o uso dos computadores, por se tratar de uma máquina iterativa, no meio desse processo de construção cognitiva pode ser aproveitável para que a criança possa adquirir mais conhecimento e suprir suas necessidades. Nesse sentido, o computador ou qualquer ferramenta tecnológica quando dotada de softwares que tem foco principal na aprendizagem, pode ser capaz de trazer bons resultados na aprendizagem do aluno.

Considerando que a química do ensino fundamental tem uma grande diferença se comparada com a do ensino médio onde nesta segunda o conteúdo é mais complexo, e o aluno, deve ser capaz de aprender todas as composições e fórmulas que ainda não havia usado, o presente estudo mostra os níveis de criação e utilização do software educacional "E-Chemical" aliado à disciplina de Química, a qual está presente na grade curricular da turma do primeiro ano do ensino médio, o qual tem como objetivo principal desenvolver a capacidade cognitiva do aluno em diferenciar as divisões existentes na tabela periódica dos elementos, bem como, promover ao aluno uma maneira diferenciada de exercitar os conteúdos apresentados em sala de aula.

\section{Desenvolvimento}

O software educacional "E-Chemical" possui como embasamento teórico para todo seu processo de criação a teoria de Seymour Papert, o qual, em seu livro A Maquina das Crianças, publicado originalmente no ano de 1993 e republicado em 2008, diz que o uso de tecnologias em sala de aula é uma maneira atraente ao aluno para fazer com que o mesmo possa ter sua aprendizagem potencializada por meio da interação homemmáquina, como também, o professor deve ser um profissional aberto a possibilidade de 
utilizar inovações em suas aulas. Com isso, o software tem como base a teoria Construcionista, uma vez que, alia tecnologia para interagir com o aluno e fazer dele agente ativo do seu conhecimento.

Para Piaget (1996) criança adquire a aprendizagem por meio da assimilação e acomodação, ou seja, ela aprende conforme o meio em que está inserido, como também, através das suas experiências, e, a partir do conhecimento adquirido ela pode buscar novas conexões, novas assimilações, novos conhecimentos e métodos para aprender, em outras palavras, o aluno monta esquemas mentais Wadsworth (1996). Os esquemas mentais são padrões de comportamento ou pensamento que surgem das mais simples e escondidas interações do indivíduo pelas quais o mesmo intelectualmente se adaptam e organizam o meio; podendo esses esquemas serem alterados com o passar do tempo, dessa forma devese estimular o aluno a criar esquemas de conhecimento, os quais ele vai modificando e aprimorando com o passar dos tempos.

O objetivo do software "E-Chemical" é fazer com que o aluno seja levado para executar missões, com recurso de Gamificação, nas quais ele deve identificar qual a classificação da tabela periódica ele pertence. O software é categorizado como jogo de exercício e prática com recurso de gamificação, fazendo com que o aluno, ao manusear o programa, seja induzido a refletir, tomar decisões e buscar melhores maneiras de resolver os problemas impostos a ele. Ou seja, a partir da assimilação ele monte esquemas mentais.

Na criação do software em questão foram utilizadas as seguintes etapas durante o seu processo de desenvolvimento: levantamento de requisitos, análise de requisitos, projeto, implementação e teste.

A fase de levantamento de requisitos foi realizada por meio de pesquisas de possíveis softwares educacionais aplicados na disciplina de Química que possam se considerados como concorrentes, os quais, após verificação, pode-se concluir que a maioria é desenvolvida com o objetivo de ser tutorial ou jogo de quis, como também, não possuem características de software gamificado, ou seja, nenhum dos encontrados correlaciona o conteúdo abordado com jogos.

Durante a fase de análise, foi definido o público alvo que poderá utilizar o programa, nesse caso, o primeiro ano do ensino médio, com o objetivo de trabalhar a coordenação, assimilação e a experiência que o aluno já possui sobre o conteúdo abordado no jogo.

Abaixo é colocado dois diagramas os quais dispõem com mais detalhes a forma na qual o software será implementado. Os diagramas de atividade e de estado demonstram que o jogador ao iniciar o jogo deve cumprir missões que estão baseadas em recolher o numero máximo de elementos ele puder, sendo que, os elementos estão organizados conforme as divisões existentes na tabela periódica, e, dependendo de seu desempenho, tem um feedback informando a quantidade de vidas ele ainda possui, quantos objetos certos foram arrecadados, em qual fase ele está jogando, bem como, o menu principal. 
VI Congresso Brasileiro de Informática na Educação (CBIE 2017)

Anais dos Workshops do VI Congresso Brasileiro de Informática na Educação (WCBIE 2017)

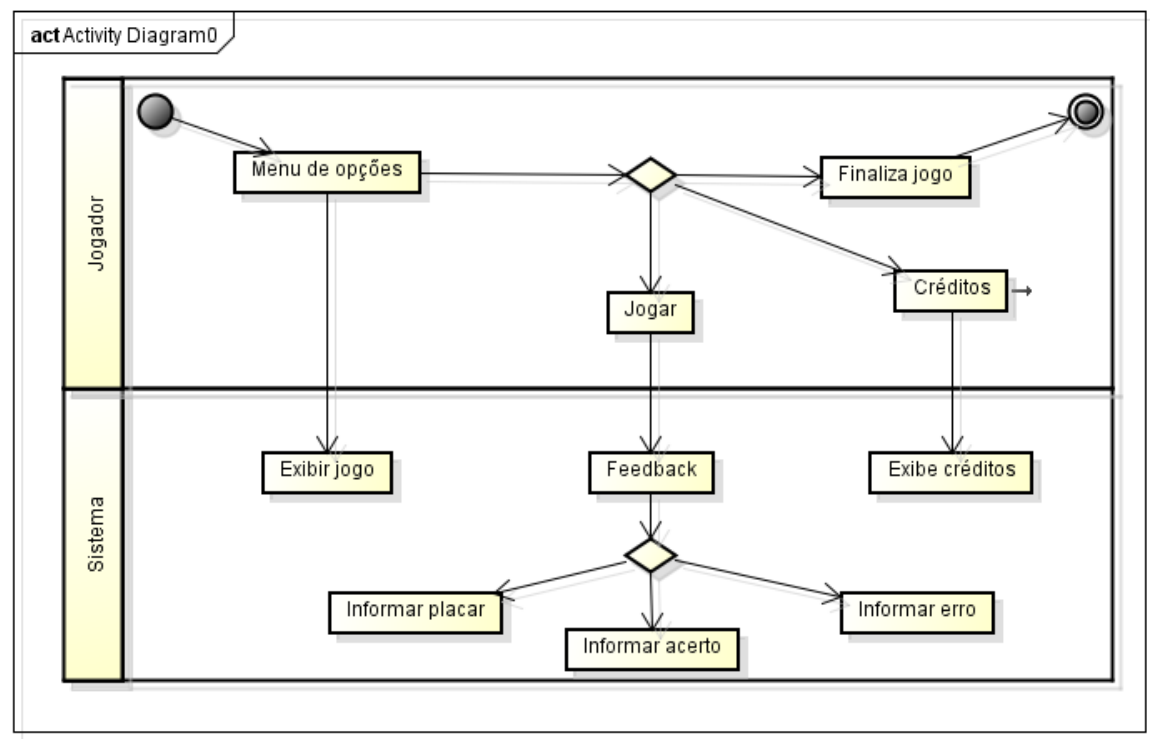

Figura 1- Diagrama de atividade

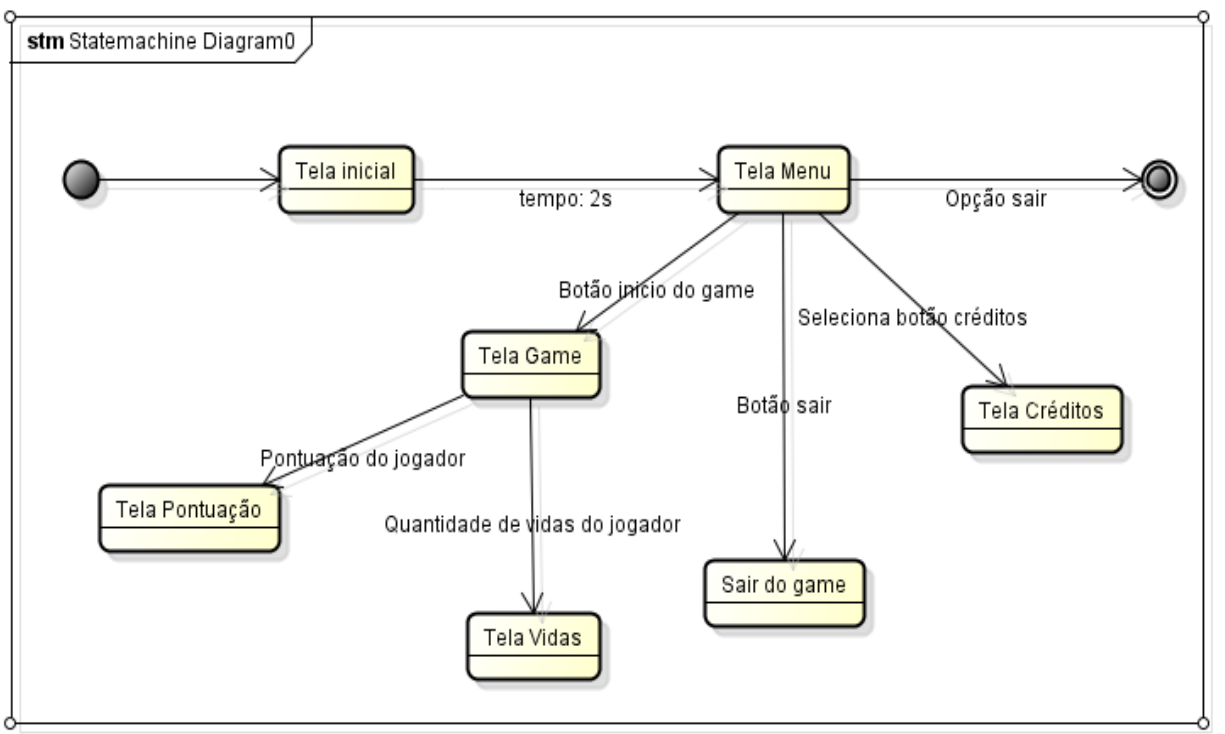

Figura 2- Diagrama de estado

A implementação do software educacional será desenvolvida por meio da plataforma de criação "Construct2" que tem como objetivo produzir jogos de browser, tanto na parte gráfica quanto na parte de programação básica e que sejam multiplataformas. A plataforma tem as opções de criar jogos em 2D. O jogo é desenvolvido para dispositivos desktop, porém, pode também ser utilizado de forma mobile como uma forma de fazer com que os alunos que possuem aparelhos celulares possam ter o software educativo sempre em mãos, podendo assim, por em prática em qualquer lugar o assunto ensinado em sala de aula.

Para a fase de teste, foi determinado que professores poderiam testar a funcionalidade do software e dar suas opiniões a respeito da utilização do jogo em sala 
VI Congresso Brasileiro de Informática na Educação (CBIE 2017)

Anais dos Workshops do VI Congresso Brasileiro de Informática na Educação (WCBIE 2017)

de aula ou até mesmo fora dela como uma forma do aluno estar sempre exercitando os conceitos.

\section{E-Chemical}

Segundo o Parâmetros Curriculares Nacionais - PCN (2000) o ensino de química para o ensino médio dever ter como característica principal contextualizar o assunto a ser abordado em sala de aula com assuntos e experiências vivenciadas pelos alunos outrora, uma vez que o ensino de química é visto pela primeira vez no ensino médio. Além disso, o conteúdo apresentado ao aluno deve tratar das transformações, códigos, símbolos e conceitos químicos básicos presentes na natureza.

Tendo em base a prioridade e o conteúdo abordado em sala de aula, a primeira fase do E-Chemical, que consiste de duas subfases, tem por objetivo principal fazer com que o jogador trabalhe sua assimilação e atenção através de um jogo no qual o aluno deve recolher o maior número possível de elementos a respeito de determinada divisão da tabela periódica. Quando ele inicia o jogo, será apresentada na tela qual a missão que ele deve cumprir, ou seja, quantos elementos de determinada divisão da tabela periódica ele deve recolher. Se ele encostar-se a um elemento errado, ele perderá uma vida. Quando ele encostar em um elemento correto é somado 1 (um) ponto em seu placar, o número máximo de elementos que ele pode recolher são 10 (dez); isso tudo deve ser feito antes que o fogo alcance o personagem a ser manuseado pelo usuário aluno. Conforme as figuras apresentadas a seguir.

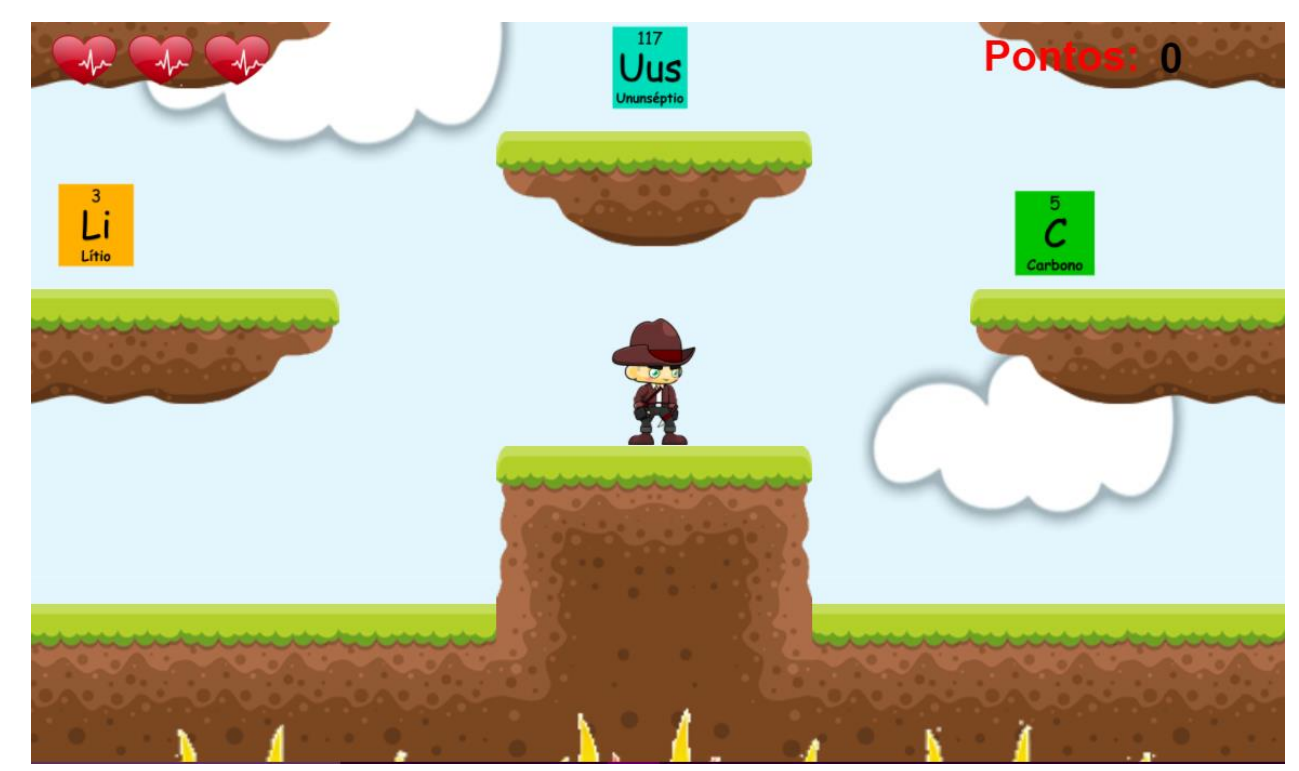

Figura 3 - Tela principal do jogo. 
VI Congresso Brasileiro de Informática na Educação (CBIE 2017)

Anais dos Workshops do VI Congresso Brasileiro de Informática na Educação (WCBIE 2017)

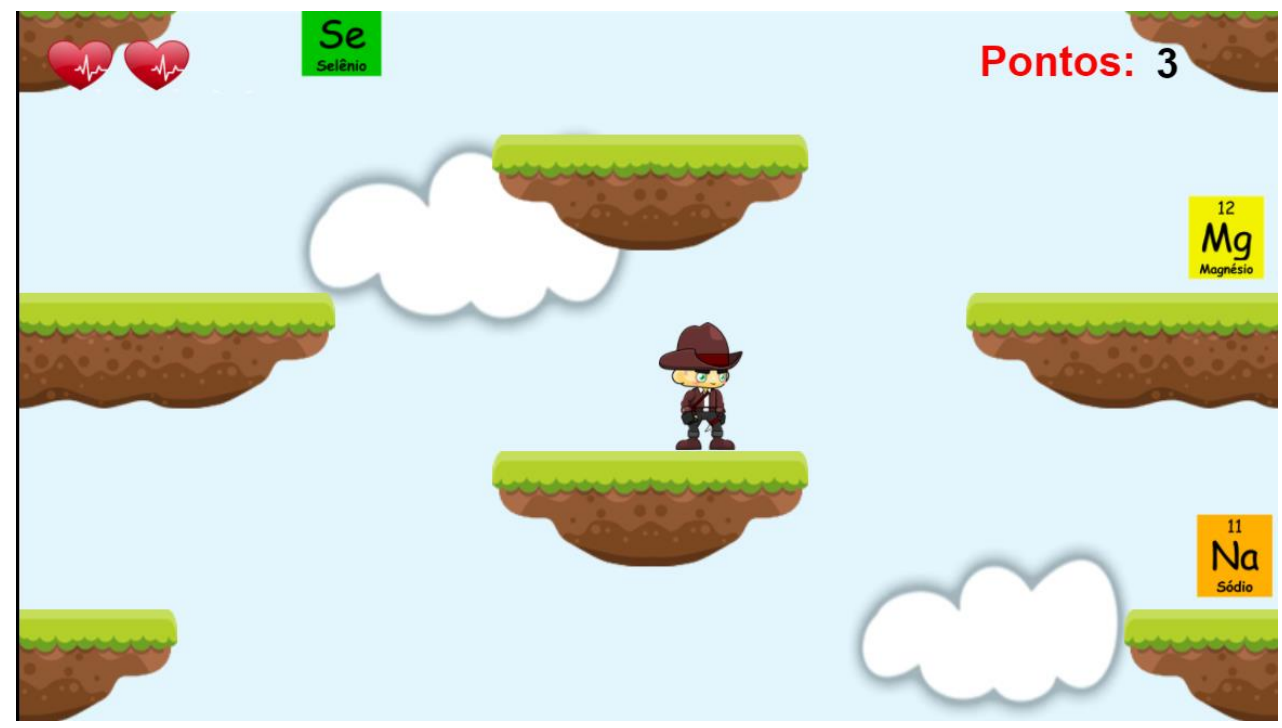

Figura 4 - Tela principal dois do jogo.

As figuras 3 e 4 apresentam a primeira subfase do jogo, que consiste no recolhimento dos elementos não-metais da Tabela Periódica. Como todos os movimentos do jogo são controlados pelo teclado do computador, o aluno pode, usando as setas do teclado, movimentar-se para cima, para baixo e para os lados direito e esquerdo para poder recolher somente os elementos característicos dessa fase. Como explicado anteriormente, se o personagem encostar em um elemento errado ele perderá 1 (uma) vida, não podendo assim perder mais de 3 (três) vidas, porém, se o jogador fazer com que o seu personagem consiga capturar os 10 (dez) elementos necessários nesta fase ele poderá passar para a próxima subfase do jogo, ilustrada a seguir; o fogo é o único vilão dessas duas subfases.

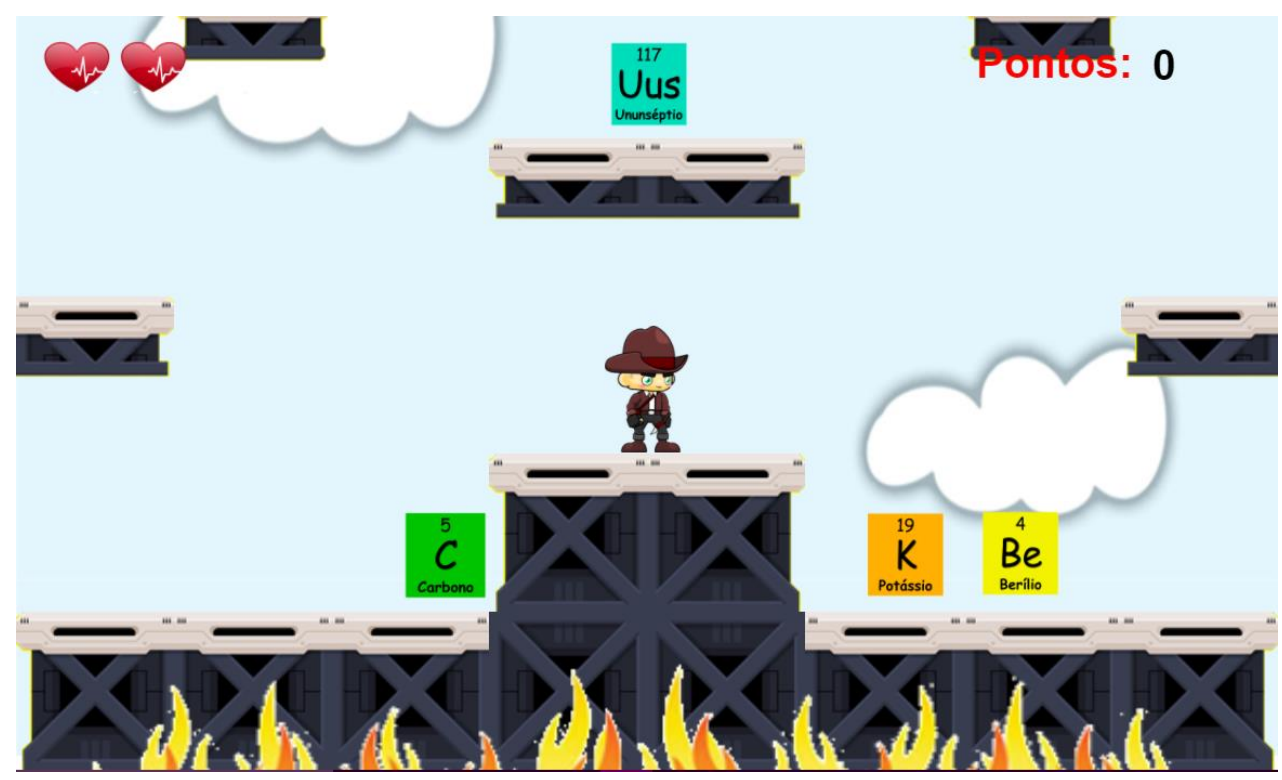

Figura 5 - Tela principal da segunda fase do jogo. 


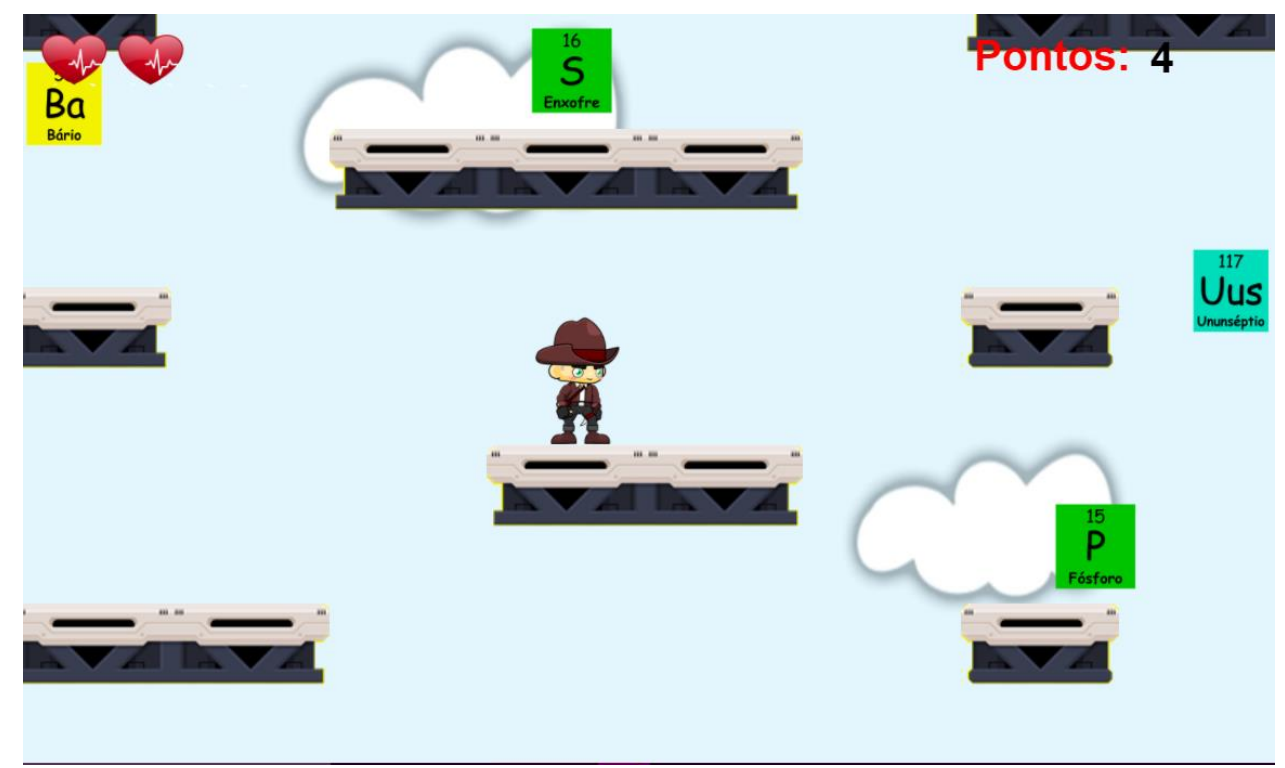

Figura 6 - Tela principal dois da segunda fase do jogo.

As figuras 5 e 6 ilustram a segunda fase do jogo, desta vez, o aluno deve capturar 10 (dez) elementos que são Metais Alcalinos. As opções de manuseio do personagem bem como o vilão desta subfase continuam sendo os mesmos, sendo que este último cresce de forma mais acelerada se comparada a subfase 1, trabalhando assim a percepção de espaço do aluno, para fazer o seu personagem pular de forma correta.

O protótipo do jogo pode ser acessado através do site: http://echemical.bitballoon.com/.

\section{Conclusão}

O desenvolvimento e aplicação do software E-Chemical no cenário educacional possibilita ao professor novas metodologias para o processo de ensino e aprendizagem do aluno, bem como, possibilita ao discente um novo meio para exercitar o conteúdo de Química; é importante salientar que a utilização do E-chemical em sala de aula pode ser uma importante ferramenta para atrair a atenção dos alunos no assunto proposto, e, pode vir a promover uma melhora na aprendizagem do mesmo. Tendo como objetivo ser um jogo que trabalhe conteúdos educacionais, o software abordado nesse estudo pode trabalhar as questões tanto disciplinares quanto questões de concentração do aluno em resolver os desafios propostos. Com isso, pode-se concluir que a utilização do EChemical em sala de aula, e fora dela também, pode trazer melhores resultados na aprendizagem dos alunos no qual o indivíduo "aprende brincando".

\section{Trabalhos futuros}

A princípio o software E-Chemical é composto das subfases mencionadas anteriormente, porém, a continuidade do jogo dar-se-á da seguinte forma:

FASE 2: O jogador poderá utilizar os elementos por ele arrecadados nas fases anteriores para poder formar elementos presentes no cotidiano humano, por exemplo, se 
o aluno recolher elementos de hidrogênio e oxigênio, logo, ele poderá na fase dois reproduzir a fórmula que compõe a água.

\section{Referências Bibliográficas}

BRASIL. Ministério da Educação. Secretaria de Educação Fundamental. Parâmetros Curriculares Nacionais: Matemática (Ensino Médio). Brasília: MEC, 2000.

KISHIMOTO, Tizuko Morchida. Brinquedo, gênero e educação na brincadeira. São Paulo: Universidade de São Paulo, 2008.

PAPERT, Seymour. A máquina das crianças. Porto Alegre: Editora Artmed, 2008.

PIAGET, Jean. Biologia e Conhecimento. $2^{\text {a }}$ Ed. Vozes : Petrópolis, 1996.

PIMENTEL, M.; Fuks, H. (organizadores). Sistemas Colaborativos. Rio de Janeiro: Elsevier, 2011.

WADSWORTH, Barry. Inteligência e Afetividade da Criança. 4. Ed. São Paulo : Enio Matheus Guazzelli, 1996. 